\title{
The Friedman-Eilber Resection Arthroplasty of the Pelvis
}

\author{
Adam J. Schwartz MD, Piya Kiatisevi MD, \\ Fritz C. Eilber MD, Frederick R. Eilber MD, \\ Jeffrey J. Eckardt MD
}

Published online: 22 April 2009

(c) The Author(s) 2009. This article is published with open access at Springerlink.com

\begin{abstract}
It has been argued that internal hemipelvectomy without reconstruction of the pelvic ring leads to poor ambulation and inferior patient acceptance. To determine the accuracy of this contention, we posed the following questions: First, how effectively does a typical patient ambulate following this procedure? Second, what is the typical functional capacity of a patient following internal hemipelvectomy? In the spring of 2006, we obtained video documentation of eight patients who had undergone resection arthroplasty of the hemipelvis seen in our clinic during routine clinical followup. The minimum followup in 2006 was 1.1 years (mean, 8.2 years; range, 1.1-22.7 years); at the time of last followup in 2008 the minimum followup was 2.9 years (mean, 9.8 years; range, 2.9-24.5 years). At last followup seven of the eight patients were without pain, and were able to walk without supports. The remaining patient used narcotic medication and a cane or crutch only occasionally. The mean MSTS score at the time of most
\end{abstract}

Each author certifies that he or she has no commercial associations (eg, consultancies, stock ownership, equity interest, patent/licensing arrangements, etc) that might pose a conflict of interest in connection with the submitted article.

Each author certifies that his or her institution has approved the human protocol for this investigation and that all investigations were conducted in conformity with ethical principles of research, and that informed consent for participation in the study was obtained.

Electronic supplementary material The online version of this article (doi:10.1007/s11999-009-0844-4) contains supplementary material, which is available to authorized users.

A. J. Schwartz ( $₫)$, P. Kiatisevi, F. C. Eilber,

F. R. Eilber, J. J. Eckardt

Department of Orthopaedic Surgery, University of California,

Los Angeles Medical Center, Santa Monica,

1250 16th Street, 7th Floor, Los Angeles, CA 90404, USA

e-mail: adamschwartz2001@yahoo.com recent followup was 73.3\% of normal (range 53.3-80.0\%; mean raw score was 22.0; range 16-24). All eight patients ultimately returned to gainful employment. These observations demonstrate independent painless ambulation and acceptable function is possible following resection arthroplasty of the hemipelvis.

Level of Evidence: Level IV, case series. See Guidelines for Authors for a complete description of levels of evidence.

\section{Introduction}

Resection arthroplasty of the pelvis is the complete removal of the innominate bone along with the femoral head and neck. It is commonly referred to as an "internal hemipelvectomy," or "flail hip," as the limb is retained [9, 11, 13, 18, 29, 30]. While Theodore Kocher is credited as the first surgeon to perform this procedure in the late 19th century [33], in 1979 Eilber et al. described a modification of that technique [18].

Instability of the residual limb following resection of the innominate bone reportedly leads to poor ambulation and inferior patient acceptance [10, 12, 14, 23, 24, 28]. As a result, most authors currently advocate replacement of the resected bone using a prosthetic device, allograft, or other means to reconstruct the pelvic ring $[3-5,7,10,17,44-46]$. We previously reported the clinical and functional results following internal hemipelvectomy without reconstruction, which has been our preferred technique since 1979 [18, 26, 40]. The prolonged rehabilitation course following this procedure as well as the consistent improvement in ambulation over time was emphasized in our previous study. Following resection arthroplasty of the hemipelvis, patients typically require ambulatory supports for at least 
one year, and are eventually able to transition to aid-free ambulation [26].

The purpose of this paper is to provide video evidence of the functional outcomes that are possible with resection arthroplasty of the hemipelvis. We posed the following questions: (1) How effectively does a typical patient ambulate following this procedure? (2) What is the typical functional capacity of a patient following internal hemipelvectomy? The accompanying video may serve as a useful reference for both patient and surgeon during the pre- and postoperative stages of primary pelvic sarcoma management. (Supplemental materials are available with the online version of CORR.)

\section{Materials and Methods}

From August 1984 to May 2006, we treated 46 patients with wide resection of portions of the innominate bone for pelvic malignancy. In the spring of 2006, one of the authors (PK) obtained video documentation for all patients who were seen in our clinic for routine followup following resection arthroplasty of the hemi-pelvis (Table 1). This included eight patients seen at a mean of 8.2 years (range, 1.1-22.7 years) following their index resection arthroplasty. The diagnosis was chondrosarcoma in four, Ewing's sarcoma in two, malignant giant cell tumor in one, and osteosarcoma in one. Six patients presented with localized disease, while two had metastatic lesions upon initial presentation. We had prior institutional board approval for the study (UCLA IRB\#G07-04-082-01) and all patients were informed that the video documentation would be used for publication, and all patients gave written consent.

All patients underwent resection arthroplasty according to the technique described by Eilber et al. [18]. Critical to the success of this particular technique is the meticulous reconstruction of the soft tissues surrounding the hemipelvis. Following resection, the remaining abductors and gluteal muscles are sutured in multiple layers to the abdominal muscles. If the anterior resection is through the symphysis, it is frequently necessary to place a prosthetic mesh to facilitate repair of the adductor musculature to the abdominal wall to help prevent herniation of the pelvic contents anteriorly. The femoral head and neck were routinely resected to avoid protrusion of the proximal femur into the pelvis. The posterior osteotomy was performed through the lateral sacrum or by disarticulation of the sacroiliac joint. Six of eight anterior osteotomies were performed through the superior and inferior pubic ramus, while the remaining two were performed through the pubic symphysis.

Surgical margins following the index resection arthroplasty were negative in all eight cases. For the eight patients, mean blood loss at surgery was $1285.7 \mathrm{cc}$ (range, 400-3500 cc) (Table 2). One patient underwent repeat surgery due to postoperative wound dehiscence, likely related to preoperative radiation therapy for his pelvic Ewing's sarcoma (Patient 7). This was managed in a single procedure with irrigation and débridement, followed by wound coverage with a latissimus dorsi rotation flap. Two patients had previously undergone iliac wing resection prior to the index resection arthroplasty. Patient 4 underwent resection of the iliac wing for intermediate-grade chondrosarcoma. Final pathologic evaluation demonstrated a positive surgical margin, and the patient was returned to the operating room within 5 days for definitive index resection arthroplasty. Similarly, Patient 6 underwent iliac wing resection for chondrosarcoma, and experienced a local recurrence 3 years postoperatively. He then underwent his index internal hemipelvectomy procedure.

Video documentation was obtained using a commercially available camcorder device by one of the authors (PK). All patients in the videos were encouraged to ambulate according to their everyday routine, and to use ambulatory aids if these were utilized routinely. Patients were instructed to ambulate approximately 30 feet, turn and return to the starting position. Next, if possible,

Table 1. Demographics

\begin{tabular}{|c|c|c|c|c|c|c|}
\hline Patient & Age & Diagnosis & Stage & Blood loss & Surgical margins & Metastatic disease \\
\hline 1 & 17 & Ewing's & III & 400 & Negative & $\mathrm{Yes}^{\S}$ \\
\hline 2 & 44 & Malignant GCT & IIB & 600 & Negative & No \\
\hline 3 & 43 & Chondrosarcoma & IIB & 1000 & Negative & Yes* \\
\hline 4 & 29 & Chondrosarcoma & IIB & 2500 & Negative & Yes $^{*}$ \\
\hline 5 & 46 & Chondrosarcoma & IIB & 500 & Negative & No \\
\hline 6 & 22 & Chondrosarcoma & IIB & 500 & Negative & Yes $^{\dagger}$ \\
\hline 7 & 23 & Ewing's & IIB & 3500 & Negative & No \\
\hline 8 & 28 & Osteosarcoma & III & NA & Negative & $\mathrm{Yes}^{\S}$ \\
\hline
\end{tabular}

$\mathrm{GCT}=$ Giant cell tumor; $* 12$ months postoperatively; ${ }^{\dagger} 10$ years postoperatively; ${ }^{\star} 3$ years postoperatively; ${ }^{\S}$ At time of presentation. 
Table 2. Results

\begin{tabular}{|c|c|c|c|c|c|c|}
\hline Patient & $\begin{array}{l}\text { Length of followup } \\
\text { (years)* }\end{array}$ & Status $^{\dagger}$ & Walking aids ${ }^{\dagger}$ & $\begin{array}{l}\text { Shoe lift } \\
\text { (inches) }^{\dagger}\end{array}$ & MSTS score & Occupation $^{\dagger}$ \\
\hline 1 & 1.1 & NED & None & 3.5 & 76.7 & College student \\
\hline 2 & 1.2 & $\mathrm{CDF}$ & Cane/crutch & 2 & 53.3 & Billing specialist \\
\hline 3 & 1.5 & $\mathrm{DOD}^{*}$ & None & 2 & 73.3 & Executive \\
\hline 4 & 6.0 & $\mathrm{DOD}^{\S}$ & $\mathrm{AFO}^{\bullet}$ & 2 & 73.3 & Artist \\
\hline 5 & 10.1 & $\mathrm{CDF}$ & None & 2 & 76.7 & Homemaker \\
\hline 6 & 10.3 & DOD $^{\prime \prime}$ & None & 0 & 76.7 & TV reporter \\
\hline 7 & 12.5 & $\mathrm{CDF}$ & None & 3 & 80.0 & Executive \\
\hline 8 & 22.7 & NED & None & 3 & 76.7 & Administrator \\
\hline Mean & 8.2 & & & 2.2 & 73.3 & \\
\hline
\end{tabular}

$\mathrm{NED}=$ no evidence of disease following treatment of metastatic lesions; $\mathrm{CDF}=$ continuously disease free; $\mathrm{DOD}=\mathrm{died}$ of disease; $\mathrm{AFO}=$ ankle-foot orthosis; MSTS = Musculoskeletal Tumor Society; *At the time of video in 2006 ; ${ }^{\dagger}$ At final followup in 2008 ; ${ }^{\star} 3.5$ years postoperatively; ${ }^{\S} 8.6$ years postoperatively; "12.3 years postoperatively; ${ }^{\text {F }}$ For nerve palsy related to subsequent spine surgery; ${ }^{\#}$ reported as percentage of normal (normal $=30$ points).

patients were instructed to navigate one flight of stairs according to their everyday routine. Functional outcomes were measured at the time of most recent clinical followup using the revised Musculoskeletal Tumor Society (MSTS) Functional Score described by Enneking et al. [21]. Scores were considered excellent if five of six variables scored five points, good if five variables scored three points or more, fair if five of six factors scored one or more points, and poor if two or more factors scored zero.

\section{Results}

Three patients who presented with Stage IIB lesions at the time of presentation developed metastatic disease at 12 months, 3 years, and 10 years postoperatively. All three of these patients died of disease in 2008 , at 3.5, 8.6, and 12.3 years, respectively, following their resection arthroplasty (Table 2). Functional data for these three patients was obtained at the time of their most recent outpatient clinic visit.

At the time of their last outpatient clinical evaluation, seven of the eight patients walked without walking assists and had no pain related to the index procedure. The remaining patient (Patient 2 ) used a cane around the house, crutches while outside, and remained on occasional narcotic medication. The mean shoe-lift size was 2.2 inches (range, 0-3.5 inches). One patient chose to ambulate without a shoe lift (Patient 6). In the absence of an ambulatory aid, all eight patients walked with a Trendelenburg gait. All patients ultimately returned to gainful employment.

The mean MSTS score at the time of most recent followup was $73.3 \%$ of normal (range, 53.3-80.0\%; mean raw score, 22.0; range, 16-24). Scores were rated as good in 7 patients, and fair in 1 .
Several key points are emphasized by the video supplement accompanying this report. First, readers should note the improvement in function that occurs as the time from the index procedure increases. Those patients with followup less than 3 years in duration demonstrate inferior ambulatory capacity to those with greater than 3 years' followup. We have found this typical of patients who have undergone resection arthroplasty of the hemipelvis, and patients are generally more accepting of this procedure at longer-term followup. Second, most patients are able to navigate stairs. The two patients who are not seen climbing stairs (Patient 1 and Patient 2) were ultimately able to achieve this capacity with the use of a rail at the time of most recent followup. Finally, readers should note the use of shoe lifts among patients in the recordings, and the function that is possible despite a substantial leg-length discrepancy. Of particular interest is Patient 6 who does not use a shoe lift, and effectively compensates by ambulating with his foot in slight equinus. (Supplemental materials are available with the online version of CORR.)

\section{Discussion}

Resection arthroplasty is a well-established procedure for conditions affecting the acromioclavicular, femoroacetabular, proximal radiocarpal, scapulothoracic, and metatarsophalangeal joints, among others [15, 22, 31, 35, 36, 42]. Despite its widespread use elsewhere, most authors decry the use of resection arthroplasty for conditions involving the pelvic girdle, citing poor postoperative function and unacceptable levels of pain. The purpose of this review was to answer the following questions: what is the typical ambulatory status of a patient following this procedure, and what is their typical functional capacity? 
The major limitations of this study include the small number of patients, the lack of an appropriately matched control group, and the potential for selection bias. Internal hemipelvectomy is only rarely indicated for pelvic malignancy and, at our institution, we averaged just over two of these procedures annually during the past three decades. With many of these patients having already succumbed to disease, and others living in distant parts of the country, it is exceedingly difficult to amass a large series. While we recognize that our study population is a select cohort, we believe these video recordings provide an accurate sample of the function that is typical following resection arthroplasty of the hemipelvis. Furthermore, the videos may serve as a useful reference for both patient and surgeon as to the typical rehabilitation course, and functional outcomes following this procedure.
All eight patients in this series were able to ambulate without pain, and without the use of walking aids. All patients walked with a Trendelenburg gait, and all but one patient required the use of a shoe-lift. It is our experience that stability of the extremity, and thus ambulation, is improved by utilizing a shoe-lift approximately $50 \%$ of the total leg-length discrepancy (eg, a 2.5-inch lift for a 5-inch leg-length discrepancy). This allows the patient to ambulate with the foot in slight equinus. If the lift equals the total leg-length discrepancy, the plantigrade foot rests on an unstable platform, which is less cosmetic and less functional than walking on the ball of the foot. The number of patients seen in this series who ambulate with a Trendelenburg gait and demonstrate a substantial leg length discrepancy is comparable to that seen in the available literature.

Table 3. Function following internal hemipelvectomy: comparison of the available literature

\begin{tabular}{|c|c|c|c|c|c|c|}
\hline Author & Year & $\begin{array}{l}\text { Number } \\
\text { of patients }\end{array}$ & $\begin{array}{l}\text { Duration of followup } \\
\text { (mean or range) }\end{array}$ & $\begin{array}{l}\text { Reconstruction } \\
\text { type* }\end{array}$ & $\begin{array}{l}\text { Functional } \\
\text { outcome }^{\dagger}\end{array}$ & Comments \\
\hline Enneking et al. [20] & 1978 & 32 & $1-17$ years & $\mathrm{A}, \mathrm{E}$ & $23 \mathrm{G}, 5 \mathrm{P}, 4 \mathrm{~F}$ & $\begin{array}{l}3 \text { with resection arthroplasty, all with } \\
\text { good function }\end{array}$ \\
\hline Johnson [27] & 1978 & 2 & $2-4.5$ years & $\mathrm{C}$ & $\mathrm{n} / \mathrm{a}$ & Both ambulate with limb, one with cane \\
\hline Steel [43] & 1978 & 5 & $3-6$ years & A & $\mathrm{n} / \mathrm{a}$ & All ambulatory without supports \\
\hline Nilsonne et al. [38] & 1982 & 7 & $1.5-10$ years & A & $\mathrm{n} / \mathrm{a}$ & Gait analysis; 1 of 7 uses no support \\
\hline Nielsen et al. [37] & 1985 & 1 & 5 years & $\mathrm{C}$ & $\mathrm{n} / \mathrm{a}$ & Pain-free, using crutch, employed \\
\hline Huth et al. [26] & 1988 & 27 & $2-14$ years & A & $\mathrm{n} / \mathrm{a}$ & $\begin{array}{l}\text { Initial ambulation with supports, } \\
\text { eventually independent }\end{array}$ \\
\hline Abudu et al. [1] & 1997 & 35 & 84 months & $\mathrm{C}$ & $70 \%$ & Thirteen of 35 available for MSTS score \\
\hline Bell et al. [8] & 1997 & 17 & 7 years & B & $70 \%$ & Thirteen of 17 available for MSTS score \\
\hline Renard et al. [41] & 1999 & 15 & 6 months & $\mathrm{C}$ & $50 \%$ & \\
\hline Kollender et al. [34] & 2000 & 27 & $1.5-12$ years & $\mathrm{A}, \mathrm{B}, \mathrm{C}$ & $6 \mathrm{E}, 17 \mathrm{G}, 3 \mathrm{~F}, 1 \mathrm{P}$ & Twelve of 27 had no reconstruction \\
\hline Pant et al. [39] & 2000 & 13 & 84 months & $\mathrm{A}, \mathrm{B}, \mathrm{C}$ & $3 \mathrm{G}, 1 \mathrm{~F}^{\ddagger}$ & $\begin{array}{l}\text { Six of } 13 \text { had no reconstruction; } \\
4 \text { patients alive at follow-up }\end{array}$ \\
\hline Wirbel et al. [46] & 2001 & 18 & 60.5 months & $\mathrm{C}$ & 3E,7G,6F,3P & \\
\hline Aljassir et al. [2] & 2005 & 17 & 45 months & $\mathrm{C}$ & $51 \%$ & \\
\hline Beadel et al. [6] & 2005 & 21 & 60 months (min) & $\mathrm{B}$ & $45 \%$ & Six of 21 available for MSTS score \\
\hline Hoffman et al. [25] & 2006 & 45 & 69 months & $\mathrm{A}, \mathrm{B}, \mathrm{C}$ & $48 \%$ & $\begin{array}{l}\text { Best function }(61 \%) \text { with } \\
\text { "hip transposition" }\end{array}$ \\
\hline Kitagawa et al. [32] & 2006 & 8 & 37 months & $\mathrm{C}$ & $53 \%$ & \\
\hline Dai et al. [14] & 2007 & 10 & 21-48 months & $\mathrm{C}$ & $7 \mathrm{G}, 2 \mathrm{~F}, 1 \mathrm{P}$ & \\
\hline Delloye et al. [16] & 2007 & 18 & 41 months & $\mathrm{B}, \mathrm{C}$ & $68 \%$ & \\
\hline Chang et al. [12] & 2008 & 6 & 18 months & $\mathrm{D}$ & $\mathrm{n} / \mathrm{a}$ & $\begin{array}{l}\text { Mean time to assist-free ambulation } \\
\text { was } 8 \text { months }\end{array}$ \\
\hline Schwartz et al. ${ }^{\S}$ & 2008 & 8 & 8.2 years & A & $22 ; 73.3 \%$ & $\begin{array}{l}7 \text { Good, } 1 \text { Fair; Video documentation } \\
\text { provided }\end{array}$ \\
\hline
\end{tabular}


A lack of standardized reporting, coupled with varied surgical techniques reported throughout the literature makes functional data comparison difficult (Table 3). The system described by Enneking et al. [21] is the most widely employed means of functional reporting following treatment of musculoskeletal malignancy. According to this system, patients are assigned a score between 0 and 5 for pain, function, supports, emotional acceptance, walking ability, and gait. Functional scores are reported as a percentage of normal (the maximum 30 possible points) [21]. An earlier scoring system [19] reported outcomes on a 35-point scale, and encouraged a more subjective terminology (e.g. excellent, good, fair and poor) used in many older series. The results of this series are compared to those reported in the available literature (Table 3). The mean MSTS score at the time of most recent followup was $73.3 \%$ of normal (range 53.3-80.0\%; mean raw score was 22.0; range 16-24), which is comparable to scores reported throughout the literature. The prolonged rehabilitation course following this procedure, which is a common finding in similar studies, should be discussed with the patient preoperatively. By 3 years, most patients are able to achieve pain-free, independent ambulation without the use of supports.

Resection arthroplasty of the hemipelvis provides an alternative to complex reconstructive procedures that carry high rates of reoperation, infection, implant failure, and amputation. Although the vast majority of patients will demonstrate a considerable leg-length discrepancy, the results of this review demonstrate that independent, painless ambulation is possible following resection of the innominate bone without reconstruction of the pelvic ring. We provide this video documentation as objective evidence for both patient and surgeon of the functional outcomes that are possible following this procedure. A lack of standardized reporting in the available literature makes comparison of the different reconstructive options difficult. In the future, increased uniformity of technique and reporting method among comparable series should be encouraged.

Acknowledgments We thank Sara Johnson, Miriam Reyes, and Thara Rankin for their assistance in the preparation of this manuscript.

Open Access This article is distributed under the terms of the Creative Commons Attribution Noncommercial License which permits any noncommercial use, distribution, and reproduction in any medium, provided the original author(s) and source are credited.

\section{References}

1. Abudu A, Grimer RJ, Cannon SR, Carter SR, Sneath RS. Reconstruction of the hemipelvis after the excision of malignant tumours. Complications and functional outcome of prostheses. J Bone Joint Surg Br. 1997;79:773-779.
2. Aljassir F, Beadel GP, Turcotte RE, Griffin AM, Bell RS, Wunder JS, Isler MH. Outcome after pelvic sarcoma resection reconstructed with saddle prosthesis. Clin Orthop Relat Res. 2005;438:36-41.

3. Apffelstaedt JP, Driscoll DL, Karakousis CP. Partial and complete internal hemipelvectomy: complications and long-term follow-up. J Am Coll Surg. 1995;181;43-48.

4. Asavamongkolkul A, Pimolsanti R, Waikakul S, Kiatsevee P. Periacetabular limb salvage for malignant bone tumours. J Orthop Surg (Hong Kong). 2005;13:273-279.

5. Baliski CR, Schachar NS, McKinnon JG, Stuart GC, Temple WJ. Hemipelvectomy: a changing perspective for a rare procedure. Can J Surg. 2004;47:99-103.

6. Beadel GP, McLaughlin CE, Wunder JS, Griffin AM, Ferguson PC, Bell RS. Outcome in two groups of patients with allograftprosthetic reconstruction of pelvic tumor defects. Clin Orthop Relat Res. 2005;438:30-35.

7. Beck LA, Einertson MJ, Winemiller MH, DePompolo RW, Hoppe KM, Sim FF. Functional outcomes and quality of life after tumor-related hemipelvectomy. Phys Ther. 2008;88:916-927.

8. Bell RS, Davis AM, Wunder JS, Buconjic T, McGoveran B, Gross AE. Allograft reconstruction of the acetabulum after resection of stage-IIB sarcoma. Intermediate-term results. $J$ Bone Joint Surg Am. 1997;79:1663-1674.

9. Bruns J, Luessenhop S, Behrens P. Cost analysis of three different surgical procedures for treatment of a pelvic tumour. Langenbecks Arch Surg. 1998;383:359-363.

10. Bruns J, Luessenhop SL, Dahmen G. Internal hemipelvectomy and endoprosthetic pelvic replacement: long-term follow-up results. Arch Orthop Trauma Surg. 1997;116:27-31.

11. Burri C, Claes L, Gerngross H, Jun RM. Total "internal" hemipelvectomy. Arch Orthop Trauma Surg. 1979;94:219-226.

12. Chang DW, Fortin AJ, Oates SD, Lewis VO. Reconstruction of the pelvic ring with vascularized double-strut fibular flap following internal hemipelvectomy. Plast Reconstr Surg. 2008;121: 1993-2000.

13. Chretien PA, Sugarbaker PH. Surgical technique of hemipelvectomy in the lateral position. Surgery. 1981;90:900-909.

14. Dai KR, Yan MN, Zhu ZA, Sun YH. Computer-aided custommade hemipelvic prosthesis used in extensive pelvic lesions. J Arthroplasty. 2007;22:981-986.

15. Darrach W. Partial excision of the lower shaft of the ulna for deformity following Colle's fracture. Ann Surg. 1913;57:764-765.

16. Delloye C, Banse X, Brichard B, Docquier PL, Cornu O. Pelvic reconstruction with a structural pelvic allograft after resection of a malignant bone tumor. J Bone Joint Surg Am. 2007;89:579587.

17. Dodge LD, Johnston JO. Internal hemipelvectomy and reconstruction for malignant primary acetabular tumors. A report of five cases. Orthopedics. 1987;10:323-327.

18. Eilber FR, Grant TT, Sakai D, Morton DL. Internal hemipelvectomy-excision of the hemipelvis with limb preservation. An alternative to hemipelvectomy. Cancer. 1979;43:806-809.

19. Enneking WF, ed. Modification of the System for Functional Evaluation of the Surgical Management of Musculoskeletal Tumors. New York, NY: Churchill Livingstone; 1987.

20. Enneking WF, Dunham WK. Resection and reconstruction for primary neoplasms involving the innominate bone. J Bone Joint Surg Am. 1978;60:731-746.

21. Enneking WF, Dunham W, Gebhardt MC, Malawar M, Pritchard DJ. A system for the functional evaluation of reconstructive procedures after surgical treatment of tumors of the musculoskeletal system. Clin Orthop Relat Res. 1993;286:241-246.

22. Girdlestone GR. Acute pyogenic arthritis of the hip: an operation giving free access and effective drainage. Lancet. 1943;241:419_ 421 . 
23. Hamdi M, Gebhart M, Recloux P. Internal hemipelvectomy. Eur J Surg Oncol. 1996;22:158-161.

24. Hoekstra HJ, Szabo BG. Internal hemipelvectomy with intraoperative and external beam radiotherapy in the limb-sparing treatment of a pelvic girdle chondrosarcoma. Arch Orthop Trauma Surg. 1998;117:408-410.

25. Hoffmann C, Gosheger G, Gebert C, Jürgens H, Winkelmann W. Functional results and quality of life after treatment of pelvic sarcomas involving the acetabulum. J Bone Joint Surg Am. 2006;88:575-582.

26. Huth JF, Eckardt JJ, Pignatti G, Eilber FR. Resection of malignant bone tumors of the pelvic girdle without extremity amputation. Arch Surg. 1988;123:1121-1124.

27. Johnson JT. Reconstruction of the pelvic ring following tumor resection. J Bone Joint Surg Am. 1978;60:747-751.

28. Karakousis CP. Internal hemipelvectomy. Surg Gynecol Obstet. 1984;158:279-282.

29. Karakousis CP. Abdominoinguinal incision and other incisions in the resection of pelvic tumors. Surg Oncol. 2000;9:83-90.

30. Karakousis CP, Emrich LJ, Driscoll DL. Variants of hemipelvectomy and their complications. Am J Surg. 1989;158:404-408.

31. Keller WL. The surgical treatment of bunions and hallux valgus. NY Med. 1904;80:741-742.

32. Kitagawa Y, Ek ET, Choong PF. Pelvic reconstruction using saddle prosthesis following limb salvage operation for periacetabular tumour. J Orthop Surg (Hong Kong). 2006;14:155-162.

33. Kocher T. Text-book of Operative Surgery. Stiles HJ, Paul CB, trans-eds. London, England: Adam and Charles Black: 1903:363.

34. Kollender Y, Shabat S, Bickels J, Flusser G, Isakov J, Neuman Y, Cohen I, Weyl-Ben-Arush M, Ramo N, Meller I. Internal hemipelvectomy for bone sarcomas in children and young adults: surgical considerations. Eur J Surg Oncol. 2000;26:398-404.

35. Linberg, BE. Interscapulo-thoracic resection for malignant tumor of the shoulder joint region. J Bone Joint Surg. 1928;10:344-349.
36. Mumford, EB. Acromioclavicular dislocation: a new operative treatment. J Bone Joint Surg Am. 1941;23:799-802.

37. Nielsen HK, Veth RP, Oldhoff J, Koops HS, Scales JT. Resection of a peri-acetabular chondrosarcoma and reconstruction of the pelvis. A case report. J Bone Joint Surg Br. 1985;67:413-415.

38. Nilsonne U, Kreicbergs A, Olsson E, Stark A. Function after pelvic tumour resection involving the acetabular ring. Int Orthop. 1982;6:27-33.

39. Pant R, Moreau P, Ilyas I, Paramasivan ON, Younge D. Pelvic limb-salvage surgery for malignant tumors. Int Orthop. 2001;24:311-315.

40. Patel MV, Eckardt JJ, Eilber FR. Resection arthroplasty of the hip-internal hemipelvectomy for malignant tumors of the pelvis: Perioperative management, operative technique, and functional outcome. Semin Arthroplasty. 1999;10:163-170.

41. Renard AJ, Veth RP, Schreuder HW, Pruszczynski M, Keller A, van Hoesel Q, Bökkerink JP. The saddle prosthesis in pelvic primary and secondary musculoskeletal tumors: functional results at several postoperative intervals. Arch Orthop Trauma Surg. 2000;120:188-194.

42. Stamm, TT. Excision of the proximal row of the carpus. Proc $R$ Soc Med. 1944; 38:74-75.

43. Steel HH. Partial or complete resection of the hemipelvis. An alternative to hindquarter amputation for periacetabular chondrosarcoma of the pelvis. J Bone Joint Surg Am. 1978;60:719-730.

44. Tunn PU, Fehlberg S, Andreou D, Kettelhack C. Endoprosthesis in the operative treatment of bone tumours of the pelvis [in German]. Z Orthop Unfall. 2007;145:753-759.

45. Wirbel RJ, Schulte M, Maier B, Koschnik M, Mutschler WE. Chondrosarcoma of the pelvis: oncologic and functional outcome. Sarcoma. 2000;4:161-168.

46. Wirbel RJ, Schulte M, Mutschler WE. Surgical treatment of pelvic sarcomas: oncologic and functional outcome. Clin Orthop Relat Res. 2001;390:190-220. 